\title{
Estado de Mato Grosso do Sul, Federação das Indústrias de Mato Grosso do Sul: políticas de educação técnica profissional
}

\author{
State of Mato Grosso do Sul, Federation of Industries of Mato Grosso do Sul: \\ professional technical education policies
État du Mato Grosso do Sul, Fédération du Mato Grosso do Sul Industrie: politiques d'éducation professionnelle et technique

\section{Estado de Mato Grosso do Sul, Federación de las Industrias de Mato Grosso del Sur: Políticas de educación técnica professional}

\author{
Jefferson Carriello do Carmo ${ }^{1}$ \\ Recebido em 30/03/2017; revisado e aprovado em 24/05/2017; aceito em 08/06/2017 \\ DOI: http://dx.doi.org/10.20435/inter.v19i1.1547
}

\begin{abstract}
Resumo: O estudo está centrado no contexto das transformações do sistema de produção capitalista a partir do final do Século XX e suas implicações nas políticas de educação profissional, por meio das ações da Federação das Indústrias em Mato Grosso do Sul e do Estado de Mato Grosso do Sul. O percurso metodológico da análise constitui na pesquisa bibliográfica, documental de cunho analítico, descritivo e interpretativo do tema. Palavras-chave: políticas educacionais; educação e trabalho; educação profissional; desenvolvimento econômico.
\end{abstract}

\begin{abstract}
The study is centered in the context of the transformations of the capitalist production system from the end of the XX Century and its implications in the policies of professional education, through the actions of the Federation of Industries in Mato Grosso do Sul and in the State of Mato Grosso do Sul. The methodological course of analysis is the bibliographical research, analytical documentary, descriptive and interpretative the theme.
\end{abstract}

Keywords: educational policy; labor and education; professional education; economic development.

Résumé: L'étude se concentre sur le contexte de la transformation du système de production capitaliste de la fin du XXe siècle et leurs implications pour les politiques de formation professionnelle, à travers les actions de la Fédération des industries dans le Mato Grosso do Sul et du Mato Grosso do Sul. L'analyse itinéraire méthodologique est dans la littérature, le document d'analyse, thème descriptive et interprétative.

Mots clés: politiques éducatives; éducation et du travail; formation professionnelle; développement économique.

Resumen: El estudio se centra en el contexto de las transformaciones del sistema de producción capitalista a partir del final del siglo XX y sus implicaciones en las políticas de educación profesional a través de las acciones de la Federación de las Industrias en Mato Grosso do Sul y del Estado de Mato Grosso do Sul. El enfoque metodológico la análisis está en la búsqueda bibliográfica, documental de naturaleza analítica y interpretativa el tema.

Palabras clave: política educativa; educación y trabajo; la formación profesional; desarrollo económico.

\section{INTRODUÇÃO}

No Brasil, a década de 1970 foi marcada com a crise do modo de produção fordista/taylorista. Nos anos posteriores, houve sinais de novas formas de organização da produção com maior intensidade entre as décadas de 1980 e 1990. Nesse período, o capital centrou-se na aceleração do desenvolvimento econômico industrial e competitivo e em tipos diferentes de trabalho, cuja base foram as novas formas de produção de conhecimento e aprendizado em que as políticas educacionais de formação para o trabalho assumem um novo e relevante papel.

\footnotetext{
${ }^{1}$ Universidade de Sorocaba (UNISO), Sorocaba, São Paulo, Brasil.
} 
Nas análises feitas por Fleury $(1994 ; 1992)$ no caso brasileiro, esses sinais nas novas formas de organização da produção encontram eco na primeira metade dos anos 1980, com as propostas inovadoras dos Círculos de Controle de Qualidade (CCQs). Nesse momento, nenhuma intervenção significativa ocorreu na forma como estava organizado o trabalho. Na segunda metade dos anos de 1980, inicia-se um processo de reanimação das atividades econômicas que se estendeu até o final dessa década. Do ponto de vista das novas formas de produção, é possível caracterizar esse período como um momento da difusão de equipamentos de base microeletrônica, momento da modernização tecnológica nas novas relações de trabalho com implicações para as políticas educacionais.

Estudos realizados por Guimarães (2004) e Leite (2003; 1995) mostram que, nos anos de 1990, é possível observar os primeiros sinais de uma nova forma de economia industrial, que obrigaram as empresas a reorganizarem seus objetivos e estratégias produtivas, imprimido a competitividade industrial. Essa década aponta em direção a um processo de transformação no âmbito da indústria brasileira, no setor secundário e terciário, em que a competitividade industrial é fator determinante para a retomada econômica do país. Nesse período, é possível observar os primeiros sinais de uma nova forma de produção, na esfera industrial e na visão empresarial. Segundo Leite (1994), essa retomada do crescimento econômico nos anos de 1990, em direção a um novo processo de industrialização, aponta para dois aspectos: a modernização tecnológica, junto com as novas formas de trabalho, e a competitividade industrial, que, por sua vez, na análise de Neves (2000), são seguidas por mudanças nas políticas educacionais, no campo do ensino de nível médio e técnico profissional. A intensidade dessas modificações e sua ampliação ocorrem por meio da inovação tecnológica, que invadiram as formas de produção no universo industrial e desenvolveram novas relações de trabalho e de produção pela via de novos padrões de gestão da força de trabalho, cujo alcance manifesta-se, também, no âmbito das políticas sociais de educação.

No campo econômico, a abertura externa é acompanhada pela instrumentalização política de alguns segmentos da sociedade civil vindo a favorecer-se das condições institucionais regulatórias que atingiram tais políticas. Essa fração da sociedade reivindica a regulamentação dessas políticas, a proteção do mercado e a flexibilização das relações de trabalho. Segundo Neves (2000; 1999), com essa abertura, tais segmentos da sociedade civil podem ser identificados, também com o empresariado enquanto uma nova classe, cuja intervenção é visível no campo político, econômico e educacional.

No campo educacional, vários estudos mostram a relação e a posição do empresariado com a educação. Nos estudos de Neves (2000; 1999), há evidências na relação e posição do empresariado frente à temática educacional nos anos de 1980, como também no início da década de 1990. Nesse período, os empresários industriais no Brasil se reestruturaram politicamente para alcançar maior capacidade de intervenção na agenda pública brasileira.

Segundo o parecer de Rodrigues (1998), o empresariado do setor industrial fortalece a Confederação Nacional de Indústria (CNI) no campo educacional, ao longo do século XX, aprimorando a sua concepção pedagógica. Nos anos finais do século, essa elaboração ganhou novos contornos frente à intensificação da concorrência intercapitalista em nível mundial. Segundo o autor, ao empresariado concebia que a educação dos trabalhadores no final do século XX precisaria tornar a força de trabalho mais eficiente, permitindo ao país se inserir na nova economia globalizada. 
Conforme analisa Oliveira (2006; 2003), o projeto empresarial de desenvolvimento econômico nos anos de 1990 vê, na educação profissional, um papel fundamental para a economia nesse período. No seu exame realizado por meio dos documentos técnicos da CNI e da Federação das Indústrias do Estado de São Paulo (FIESP), identifica a atuação das lideranças empresariais em diversos periódicos. Identifica que a ênfase dos empresários é ajustar a educação brasileira aos interesses econômicos, e suas propostas no campo da educação profissional têm como prerrogativa as propostas do Banco Mundial.

No entendimento de Neves (2005), é possível verificar que as ações empresariais na educação na atualidade se materializam como expressão política de um amplo movimento, com a finalidade de afirmar no país algumas referências que atualizem o padrão cultural de sociabilidade frente às exigências da chamada "sociedade do conhecimento".

No caso do Estado de Mato Grosso do Sul (MS), entre os anos de 1980 e 1990, é possível identificar que o processo de industrialização observado, por meio de alguns documentos elaborados e criados pelo governo do Estado, permite identificar algumas de suas estratégias criadas com a intervenção do empresariado sul-mato-grossense. Tais documentos visam programar e acelerar o processo de industrialização, bem como as políticas educacionais de profissionalização, nos limites das mudanças ocorridas no processo de produção e trabalho no Estado.

Vários estudos e documentos revelam que a política econômica do Estado de Mato Grosso encontra eco a partir dos anos de 1970 (SENNA, 2000; CARMO, 2011; LAMOSO, 2011; BRASIL, 1971; BRASIL, 1975; 1973) e trazem no seu bojo algumas especificações pertinentes ao Estado, por exemplo, a agroindústria e a indústria de transformação. Com a divisão do Estado em 1977, nos anos seguintes, é possível constatar novas formas de planejamento industrial, no âmbito estatal, com demandas produtivas e sociais implementadas por políticas econômicas e sociais, cuja prioridade centra-se nos setores secundários e terciários. Seguindo as diretrizes nacionais e internacionais, é possível identificar, nos anos entre 1986-1990, que o governo do Estado priorizou o crescimento e a modernização econômica, por meio da transformação da estrutura produtiva de primária para secundária, entrando na lógica da economia globalizada. Esse crescimento e essa transformação passam, no mínimo, por dois agentes: o Governo do Estado de Mato Grosso do Sul, por meio de políticas de incentivos fiscais, e pela intervenção da Federação das Indústrias do Estado de Mato Grosso do Sul (FIEMS).

Diante das transformações das novas formas de organização produtiva capitalista, o objetivo do estudo é identificar as ações do Estado do MS e da FIEMS sobre as políticas de educação profissional e técnica por meio de alguns documentos. O percurso metodológico da análise constitui na pesquisa bibliográfica e documental de cunho analítico, descritivo e interpretativo do tema.

\section{O NOVO EMPRESARIADO NAS DÉCADAS DE 1980 E 1990}

Segundo Neves (1999), o início dos anos de 1990 foi marcado pela suspeita da incapacidade do Estado em administrar a crise econômica, tendo em vista, o fracasso dos sucessivos planos de estabilização econômica implementados no decorrer dos anos 1980. Nesse período, há percepções de que o processo de expansão econômica no Brasil não tinha condições necessárias para o ingresso na terceira revolução industrial capitaneada pelos setores de informática e microeletrônica, na qual os países avançados se engajaram desde o início dos anos de 1980.

Outro aspecto relevante nesse período analisado por vários autores de diferentes formas (BIANCHI, 2010; DINIZ; BOSCHI, 1993; DINIZ; BOSCHI; SANTOS, 2000; CRUZ, 1995) foram as 
mudanças de interesses do empresariado industrial no final do século XX e início do século XXI. Conforme analisa Diniz e Boschi (1993), os interesses podem ser identificados das seguintes formas: na diversificação da estrutura empresarial e sua expansão, por meio de organizações corporativas oficiais e por associações independentes (ou paralelas) possibilitando a "flexibilização da estrutura global de representação de interesses na medida em que, criando canais adicionais, permitiu a atenuação da rigidez determinada pelo princípio corporativo do monopólio da representação" (DINIZ; BOSCHI, 1993, p. 116). Esses interesses tinham como meta a modernização dessas organizações corporativas com a CNI. "Tal modernização implicou basicamente maior representatividade e capacitação técnica das entidades, sobretudo tendo em vista o enfrentamento do movimento sindical" (DINIZ; BOSCHI, 1993, p. 116).

Segundo a análise de Diniz e Boschi (1993, p. 116), "com o advento da Nova República em 1985, os empresários passaram a ter uma presença mais ativa na arena política propriamente dita, disputando cargos eletivos em diferentes níveis". Essa presença ocorre pela eleição de uma bancada expressiva para o Congresso Constituinte vindo representar vários Estados e municípios. Essa representatividade pelos cargos executivos possibilitou um papel ativo nos debates da Constituinte "quer através da prática de lobby, quer através de uma ação mais coordenada no âmbito de entidades de cúpula como a CNI e a União Brasileira de Empresários (UBE), esta última criada com a finalidade precípua de influir na elaboração da nova Constituição" (DINIZ; BOSCHI, 1993, p. 116).

Na década de 1990, é possível identificar o surgimento de novos tipos de organizações, entre as quais podemos destacar o Pensamento Nacional das Bases Empresariais (PNBE), o Instituto de Estudos para o Desenvolvimento Industrial (IEDI) e os Institutos Liberais. Essas organizações, segundo Diniz e Boschi (1993), não estão diretamente voltadas para a representação de seus interesses, mas para "a formulação e difusão de visões alternativas que contemplam, desde a redefinição do papel do empresariado no processo de desenvolvimento do país, até, em alguns casos, a elaboração de um projeto nacional" (DINIZ; BOSCHI, 1993, p. 116). A difusão dessas visões, para Diniz e Boschi (1993, p. 116), centra-se em "questionar as formas de atuação das entidades tradicionais de representação de interesses da classe empresarial e pelo esforço de superação de uma visão particularista, setorial e de curto prazo, típica dos padrões convencionais de comportamento do empresariado". Tais questionamentos, segundo Diniz e Boschi (1993, p. 117)

[...] apontam para a ruptura da imagem tradicional associada aos empresários brasileiros e dependente do Estado. Em consequência da tradição corporativa e do padrão histórico de relacionamento empresário/Estado, a baixa legitimidade do sistema capitalista reflete-se tanto na percepção do empresário enquanto avesso ao risco e a um enfrentamento dos conflitos de classe, quanto na avaliação da própria economia de mercado. Por fim, constitui também um traço das novas organizações, sobretudo no que diz respeito ao PNBE e ao IEDI, a tendência a estimular uma visão mais moderna acerca das relações com o mundo do trabalho, rompendo com a postura avessa à negociação, mais característica do empresariado como um todo em diferentes momentos do processo de industrial.

Ainda, no entendimento de Diniz e Boschi (2000), ao referirem sobre "globalização, herança corporativa e a representação dos interesses empresariais: novas configurações no cenário pós-reformas" reconhecem que o impacto da crise a partir dos anos de 1970 criou a necessidade de novas formulações para o capitalismo nacional, essas de cunho neoliberal constituindo, dentre outras coisas, no desmantelamento da economia desenvolvimentista, em que cumpre, dentre 
outras ações, a reforma do Estado brasileiro. Segundo Diniz e Boschi (2000, p. 16), essa reforma foi atribuída a um legado coorporativo, centrado no "padrão de atuação do empresariado, e as novas conformações da estrutura de representação dos seus interesses ocorrem sob o impacto do arcabouço institucional corporativo e das sucessivas mudanças nele introduzidas pelos próprios empresários ao longo do tempo".

Para Giacalone (1997), o estudo sobre as "asociaciones empresariales integración y Estado Colombia y Venezuela" mostra que as mudanças que ocorrem na estrutura empresarial estão inerentemente atreladas com o Estado. Ao colocar em destaque essas relações entre o Estado e as associações empresariais, evidencia que o modelo ideológico presente nessa relação é a economia internacional e o neoliberalismo que colocam o setor privado como central no processo econômico.

Para Durand (1997), a participação dos empresários latino-americanos no processo de redemocratização a partir dos anos de 1980 é de implementação de ajustes estruturais, por meio de uma ação técnico-burocrática de orientação neoliberal, os quais incluem mudanças produzidas na relação entre o Estado e os empresários, em que estes têm influências significativas principalmente em políticas sociais específicas, no nosso caso de análise às políticas de educação profissional. Continua o autor: não há dúvidas de que o processo de mudança atualmente em curso na economia e do setor privado, em parte, é resultado da própria ação empresarial; esta, manifestada nas suas associações e dirigentes, é também decorrência de amplas e completas alianças de forças (externas e internas) que vão criando as condições para alterar as funções do Estado quanto às políticas públicas. Essas mudanças de alcance macroeconômico têm forçado os empregadores a adaptar-se às novas regras impostas pela forma em que vem ocorrendo, por conta dos ajustes estruturais a partir do final dos anos 1980 e início dos anos 1990, viabilizando o fortalecimento dos empresários como agentes econômicos e como atores políticos. Nesse processo de fortalecimento e de reestruturação do empresário, há várias ocorrências: menor dependência do estado em assumir alguns setores públicos, compartilhar da economia com o capital estrangeiro; ter maior influência das instituições empresariais no campo político e econômico e viabilizar a entrada de empresários no campo político, com vista a tornarem-se ministros, assessores e até presidentes.

Conforme analisa Bianchi (2004), entre as décadas de 1980-2000, o impulso associativo dos empresariados latino-americano ocorreu, por meio, das complexas relações com a ação estatal e como uma das respostas capitalistas possíveis à crise do capitalismo latino-americano. Essa resposta assume uma forma institucional, por meio de projetos empresariais que se desenham no contexto da crise econômica e política do continente, potencializando a alternativa neoliberal, via o empresariado latino-americano. A institucionalização do associativismo empresarial, nesse período na América Latina, segundo o autor, desempenhou um papel decisivo para a transformação do ambiente ideológico, por meio da difusão de uma concepção de mundo liberal visando à mudança da agenda política e econômica, em um período em que o Estado recua das suas posições ocupadas antes da crise.

Cruz (1995) sustenta que há a ocorrência de uma campanha contra o estado aderida por uma grande parcela dos empresários. Essa adesão estava no cerne da transição da economia para bens de capital, e como tal passagem ganha magnitude nas novas formas de trabalho e produção no âmbito de uma moderna economia, que indica um novo caminho a ser seguido pelo empresariado. 


\section{A CRIAÇÃO E EXPANSÃO DO SISTEMA DA FIEMS}

Os estudos indicados aqui sobre a nova constituição dos empresários a partir do esgotamento do modo de produção fordista/taylorista sugerem a intervenção desse segmento civil nas políticas econômicas e sociais. Essa ingerência do empresariado ocorre no contexto das transformações da organização produtiva capitalista, cujo reflexo é visível nas ações do Estado do MS e na criação e expansão do sistema da FIEMS.

A criação e expansão do sistema da FIEMS ocorre no surgimento do Estado de Mato Grosso do Sul e nas transformações socioeconômicas ocorridas entre as décadas de 1970-1980. Com o advento do Estado, foram desenvolvidos vários programas econômicos, cujo objetivo foi ampliar a sua economia. Dentre os programas, estava o já previsto na Lei Complementar n. 31 de 11/10/1977, o Programa Especial do Desenvolvimento de Mato Grosso do Sul (PROSUL), cujo objetivo geral e específico centra-se na

[...] promoção do desenvolvimento econômico, além de dois objetivos específicos que vieram no bojo da política nacional de desenvolvimento: $1^{\circ}$ ) ampliar a produção de produtos alimentares básicos, como trigo, por exemplo, em grande parte importado, para aliviar a balança comercial da carga de importações, sobrecarregada com a alta do dólar e a crise do petróleo e ampliar a exportação de produtos agropecuários como a soja e a carne; $2^{\circ}$ ) promover a agroindústria no sentido de beneficiar as matérias-primas regionais. (ABREU, 2001, p. 213-4).

No bojo desse desenvolvimento, estava o processo de industrialização do Estado, que, Segundo Zamberlan et al. (2010, p. 133),

[...] iniciou como modelo de substituição de importações estaduais, criando pequenas indústrias destinadas a suprir a demanda interna por bens de consumo não duráveis. Essa pequena indústria se formou impossibilitada de competir com aquelas localizadas nos grandes centros industriais do país, e talvez, por esse motivo, não houve um crescimento relevante desses setores industriais. No entanto, por pressão dos agropecuaristas, que viam a necessidade de indústrias na região voltadas ao beneficiamento de suas produções, começaram a se formar complexos agroindustriais, o que explica a concentração desse setor em Mato Grosso do Sul em comparação com o país.

Com a integração do Estado de MS no Conselho de Desenvolvimento e Integração Sul (CODESUL) em 1992, a preocupação central do governo foi planejar as áreas mais dinâmicas do Estado para os investimentos econômicos, em que se priorizaram as recomendações emitidas pelos Planos Nacional de Desenvolvimento (PND). Isso fica comprovado com a criação do Núcleo Industrial de Campo Grande, em 1977, pela Prefeitura Municipal que o gerenciou até 1979, quando passou a ser administrado pelo Estado (CODESUL, 2017).

Em 6 de novembro de 1979, foi criada a FIEMS, na capital do Estado urbe de Campo Grande. No dia 13 de novembro, reconhecida oficialmente pelo Ministério do Trabalho e Emprego, conforme Resolução n. 323.051/79, publicada no dia 21 de novembro no Diário Oficial da União. Além disso, dados indicados por Fernandes (2009) mostram que a gênese da FIEMS aconteceu no núcleo da Federação das Indústrias do Estado de Mato Grosso (IEMT).

Segundo Zamberlan (2010), logo após a sua criação, há pressão dos empresários do setor primário e secundário por meio da FIEMS, ao final de 1983, cobrando do governo estadual um posicionamento frente à industrialização do Estado, o que gerou, em março de 1984, a Lei n. 440, primeira de incentivos a indústria em Mato Grosso do Sul. 
[...] essa lei foi importante na industrialização do Estado, pois incentivou diversos projetos industriais e demonstrou aos investidores, principalmente com a criação do Conselho de Desenvolvimento Industrial, disposição, de ao menos, discutir um processo de industrialização regional com coparticipação do aparelho burocrático. Fora isso, posteriormente foram elaboradas as leis 701, que incentivou 125 projetos e a lei 1239, que abriu caminho para mais 71. Essas três leis de incentivo a industrialização fizeram com que várias unidades agroindustriais fossem implantadas no estado após 1985 e que criaram mais de 3000 empregos diretos, já naquele ano. Foram criadas esmagadoras de soja, moinhos de trigo, frigoríficos, fecularias, laticínios, usinas de açúcar, entre outras. (MICHELS et al., 2001 apud ZAMBERLAN et al., 2010, p. 126).

Esse fator de crescimento econômico tem como destaque o setor secundário e assume um papel relevante para a economia do Estado e para o Município de Campo Grande, propiciou o fortalecimento da agropecuária no Estado que começou a mudar nos anos posteriores. O Estado continuou investindo em toda a Região Centro-Sul com uma "política de atração", seguida do processo de desconcentração da indústria dos grandes centros. Essa iniciativa parte dos governos Federal, Estadual e Municipal, que oferecem isenções fiscais e de infraestrutura para a instalação de empresas (FIEMS; SENAI, 2008). Com esses incentivos para a industrialização no Estado, a FIEMS, por meio do seu primeiro presidente Jorge Zahran, estabelece objetivos para a consolidação das indústrias locais, mediante o fortalecimento das unidades do SESI e do SENAI já existentes no Estado. Segundo Zahran (2009, p. 8), "Mato Grosso do Sul tinha apenas a unidade do SESI na Avenida Afonso Pena e uma unidade em Três Lagoas [...]. Também possuíamos em Corumbá uma unidade do SENAI, que foi implantada pelo Governo Federal para atender os funcionários de uma usina de cimento". Contudo, em virtude dos altos custos gerados pelas referidas escolas profissionalizantes, a recém-fundada FIEMS não conseguia mantê-las, sendo necessário o subsídio da Confederação Nacional das Indústrias (CNI).

Durante muito tempo a CNI manteve as duas entidades por meio do Sesi Nacional e Senai Nacional. Hoje, no entanto, todas as unidades do Sistema no Estado foram construídas e estão sendo mantidas pela FIEMS. Após a construção do Sesi e Senai, partimos para conceber um local para a realização dos eventos. Assim, no prazo de 90 dias, construímos o Centro de Convenções e Exposições Albano Franco para a realização da 2a Feira Industrial do Estado, no dia 26 de novembro de 1988. (ZAHRAN, 2009, p. 8).

No final da década de 1980 e nas décadas posteriores, com os investimentos no âmbito industrial e nos setores primário e terciário, há uma preocupação centrada em projetos diversos situados na formação profissional que receberam o incentivo da FIEMS. De forma particular, no ano de 2009, segundo Sergio Marcolino Longen, Presidente da FIEMS, a instituição mantinha a execução de projetos no valor de 35 milhões de reais, destinados a ampliar e modernizar os serviços de atendimento as indústrias, e a promover a reforma de algumas unidades escolares, tais como a Escola da Construção em Campo Grande e o Sesi Total em Três lagoas. Para Longen (2009), os investimentos iriam beneficiar em média 86 mil pessoas e mais de 800 empresas.

No período entre 2008 a 2009, a FIEMS construiu 15 bibliotecas da Indústria e do Conhecimento do SESI, visando facilitar o acesso à informação em mídia digital e impressa aos trabalhadores e seus familiares. Tais unidades foram instaladas nas seguintes cidades:

Corumbá, Três Lagoas (duas), Sidrolândia, Aquidauana, Campo Grande (três unidades), Ponta Porã, Nova Andradina, Rio Verde de Mato Grosso, Naviraí, Bataguassu, Costa Rica e Iguatemi, todas dotadas com acervo de 1,6 mil livros, dezenas de DVDs e CDs e dez computadores com acesso à internet. (FIEMS, 2009a, p. 7). 
Dados extraídos da própria FIEMS, no que concerne à qualificação educacional, houve investimentos na educação básica e na qualificação de mão de obra. Na modalidade de Educação de Jovens e Adultos (EJA), a entidade investiu no SESI, que disponibiliza em média 500 vagas, e no SENAI, que oferece 5,3 mil vagas, sendo 3,4 mil em 27 cursos de qualificação e 1,9 mil para os cursos de aprendizagem industrial (FIEMS, 2009b). Esses cursos atenderam as cidades de Campo Grande, Três Lagoas, Dourados e Corumbá (FIEMS, 2009b, p. 28-9). Quanto ao SENAI, as vagas gratuitas para o Ensino Profissional são oferecidas entre as unidades das cidades de Campo Grande, Corumbá, Dourados, Naviraí, Nova Andradina, Rio Verde de Mato Grosso, Sidrolândia e Três Lagoas.

No ano de 2009, segundo os dados fornecidos pela FIEMS (2009c), houve a ocorrência por meio do projeto FIEMS Inova, a reunião um conjunto de 12 projetos, sendo estes: Eficiência Energética; Estruturação da Área de vendas Industriais; Gestão em Logística; Melhores Práticas de Gestão em RH; Missões Empresariais; Programa Alimento Seguro- PAS; Planejamento e Gestão Empresarial; Planejamento tributário empresarial; Construir; Relações de Trabalho e Avaliação de Risco; Senai Solidário; Software de Gestão Industrial. Esses projetos foram "destinados a ampliar a participação dos diretores da entidade nas atuações e nos projetos integrados da Federação" (FIEMS, 2009c, p. 10), com objetivo de desenvolver projetos que dessem sustentação ao desenvolvimento industrial no Estado (FIEMS, 2009c), visando à consolidação do setor industrial de Mato Grosso do Sul. A soma de investimentos foi em um total de $R \$ 3.479 .110,24$, destinados a envolver 410 empresas e a realizar 505 atendimentos, beneficiando 2.726 pessoas.

De forma geral, a criação da FIEMS em parceria com o Estado de MS trouxe uma crescente industrialização e a diversificação dos polos produtivos em vários munícipios, como também no trabalho do campo com a implementação do agronegócio e vários projetos de educação para o trabalho, cuja finalidade foi qualificar mão de obra para uma economia em crescimento, nos vários setores em desenvolvimento.

\section{EDUCAÇÃO PROFISSIONAL E ENSINO TÉCNICO PROFISSIONAL NO ESTADO DE MATO GROSSO DO SUL}

No contexto das transformações econômicas e políticas do Estado de MS, houve também a sua crescente participação no processo de institucionalização da educação profissional, por meio das legislações educacionais.

O primeiro documento sobre o ensino técnico profissional no Estado de Mato Grosso do Sul é datado em 20 de março de 1980, Resolução SED n. 016, que reconheceu as habilitações em Técnico em Eletrotécnica e Técnico em Enfermagem, autorizados pelo Estado em 4 de janeiro de 1980, e oferecidas na Escola Técnica Marechal Rondon, na cidade de Três Lagoas. Evidentemente, tais cursos estavam compreendidos no contexto da reforma do Ensino Médio, a qual transformou o Ensino Ginasial e a Educação Secundária em Ensino de 1ㅇ e 2o Graus respectivamente. Na Constituição do Estado do MS 1989, o ensino técnico profissional é mencionado, sendo prerrogativa do Estado estimular "diretamente ou através de incentivos fiscais, a criação e a expansão do ensino técnico e [...] de agropecuária, [...] ministrados gratuitamente ou através de bolsas de estudo". No artigo seguinte, Art. 196, da referida Constituição, assegura aos alunos dos cursos profissionalizantes mantidos pelo Estado e pelos Municípios, o direito de realizarem o Estágio Supervisionado em entidades subvencionadas pelo Estado. Na sequência, o Art. 206 aponta como 
dever do Estado, assegurar à criança, ao adolescente e ao jovem o direito a Profissionalização; no Art. 232, referindo-se a políticas de Estado voltadas para o campo, menciona que o Estado deve implantar e manter "núcleos de profissionalização específica" destinado ao homem do campo, levando em conta "as peculiaridades locais, visando desenvolver e consolidar a diversificação e a especialização regionais".

No âmbito das políticas educacionais de educação profissional, é possível identificar, nos anos posteriores à década de 1990, várias Deliberações do Conselho Estadual de Educação (CEE), no Estado, referentes a essa modalidade educacional, das quais citamos: CEE/MS n. 6.321/2001, que fixou as normas para o Sistema Estadual de Ensino no que diz respeito à oferta da Educação Profissional de nível técnico. Segundo o Art. 1, "a Educação Profissional de nível técnico compreende a Qualificação Profissional de nível técnico e a Habilitação Profissional [...], bem como a Especialização Profissional de nível técnico". Quanto às instituições que poderiam oferecer tais modalidades de ensino, o Estado aponta as instituições públicas e privadas de ensino, deixando a possibilidade de empresas, sindicatos, associações de classe e outras entidades firmarem convênios com aquelas, para atenderem uma clientela específica. Quanto à abertura dos cursos, o Artigo 3 da deliberação condiciona-os à aprovação do Conselho Estadual de Educação (CEE/MS), dado que tal órgão é o responsável pela Autorização de Funcionamento deles pelo Credenciamento da instituição para a área profissional pretendida.

Além dos documentos acima descritos, a Deliberação CEE/MS n. 7.014, de 16 de maio de 2003, suprimiu o § 4ㅇ do Art. 16 da mesma Deliberação, que determinava que "a instituição de ensino, ao encaminhar o Projeto do novo curso, ficará isenta da apresentação dos documentos previstos nos incisos I e II do art. 5ㅇ” (CEE/MS n. 6.321/2001, Art. $16 \S 4$ ). Dessa forma, observamos que, ao abrir um novo Curso Técnico, as escolas que já possuem essa modalidade de ensino devem apresentar apenas os documentos previstos no inciso II e III.

A Deliberação CEE/MS n. 7.014, de 16 de maio de 2003, que acrescentou o § 3으o no Art. 5응 da Deliberação CEE/MS n. 6.321, de 17 de agosto de 2001, com o objetivo de isentar as instituições de ensino que já possuem um curso técnico em funcionamento, de apresentar, novamente, no processo de abertura de um novo curso, os documentos solicitados no Inciso I do Artigo 5. Tais documentos são:

I - Da mantenedora - pessoa jurídica: comprovante de constituição e funcionamento da entidade mantenedora com a juntada, em cópia, dos seguintes documentos: a- inscrição e registro na Junta Comercial, para firmas individuais e sociedades comerciais ou registro do Estatuto Social no Cartório de Registro de Títulos e Documentos, quando se tratar de sociedades comerciais, civis ou fundações; b- inscrição no Cadastro Nacional da Pessoa Jurídica; c- Ata de constituição da Diretoria, devidamente registrada no Cartório de Registro de Títulos e Documentos, exceto de firma individual; $d$ - prova de regularidade relativa à Seguridade Social e ao Fundo de Garantia pelo Tempo de Serviço; e- prova de regularidade para com o Ministério da Fazenda, as Secretarias da Fazenda Estadual e Municipal ou outra equivalente, na forma da lei; $f$ - demonstração de patrimônio e capacidade financeira própria para manter instituições de ensino; g- Certidão Negativa de antecedentes criminais, estadual e federal, do dirigente.

A Deliberação CEE/MS n. 7.860, de 16 de setembro de 2005, sobre o Estágio Supervisionado, no Sistema Estadual de Ensino de Mato Grosso do Sul, legislando sobre a oferta do Estágio Supervisionado na Educação Profissional Técnica de nível médio, no Curso Normal Médio e no Ensino Médio e suas modalidades, encontra-se inserida no contexto do decreto n. 5.154, de 23 
de julho de 2004, que revogou o decreto 2.208/97; porém manteve a modalidade de ensino profissional concomitante ao ensino médio e sequencial e permitiu a articulação entre o ensino médio e a educação profissional, denominando-o de ensino médio integrado. Nesse sentido, a Deliberação CEE/MS n. 7.860/2005, ao se referir ao Ensino Médio, faz referência ao "ensino Médio e suas modalidades" (CEE/MS n. 7.860/2005, Art. 1ํ), de forma a contemplar as variações do Ensino Médio previstas no decreto n. 5.154/04.

Quanto ao Estágio, definido pela Deliberação CEE/MS n. 7.860/2005, este é entendido como "procedimento didático-pedagógico e ato educativo, é atividade curricular supervisionada e deve constar na Proposta Pedagógica, no Regimento Escolar e no Projeto de Curso, quando for o caso" (CEE/MS n. 7.860/2005, Art. 2ํ). A Deliberação em questão propõe as seguintes modalidades de Estágio: Estágio Profissional Obrigatório; Estágio Profissional não Obrigatório; Estágio Sociocultural ou de Iniciação Científica Obrigatório; Estágio Sociocultural ou de Iniciação Científica não Obrigatório; Estágio Civil. Tais estágios, segundo a Deliberação CEE/MS n. 7.860/2005, devem ser realizados em locais que possibilitem aos estudantes, condições de realizarem "experiências profissional, civil, sociocultural ou científica, por meio de participação em situações reais de vida e de trabalho" (CEE/MS n. 7.860/2005, Art. 4ㅇ).

No ano de 2008, o Conselho Estadual de Educação de Mato Grosso do Sul implantou, no Sistema Estadual, o Catálogo Nacional de Cursos Técnicos de Nível Médio (CNCT), mediante a Deliberação CEE/MS n. 8.830 de 1ำ de agosto de 2008. O referido Catálogo "organiza os cursos de Educação Profissional Técnica de nível médio por eixos tecnológicos e apresenta as denominações dos cursos com todas as suas exigências" (CEE/MS n. 8.830/2008, Art. 1ํ). Tal Deliberação visava integrar os Cursos Técnicos oferecidos no Estado às determinações do Ministério da Educação e consolidar o Ensino Técnico no Estado, seguindo as orientações nacionais.

Em linhas gerais, constatamos que a Educação Profissional no Estado de Mato Grosso do Sul seguiu as políticas educacionais empreendidas pelo Ministério da Educação e, de forma gradativa, consolidou o Ensino Médio profissionalizante como uma alternativa para a formação para o trabalho. Isso é possível verificar por meio da Resolução n. 1, de 3 de fevereiro de 2005, que "atualiza as Diretrizes Curriculares Nacionais definidas pelo Conselho Nacional de Educação para o Ensino Médio e, para a Educação Profissional Técnica de nível médio, as disposições do Decreto n. 5.154/2004" (BRASIL, 2005).

Essa atualização, ao que nos parece, no Estado de Mato Grosso do Sul, por meio da Deliberação CEE/MS n. 7.014/ 2003, já buscou desburocratizar aspectos legislativos aplicados na deliberação CEE/MS n. 6.321/2001, de modo a facilitar a abertura de novos cursos técnicos em Escolas que já possuíam essa modalidade de ensino em andamento.

\section{O ENSINO TÉCNICO INTEGRADO AO ENSINO MÉDIO NO ESTADO DE MATO GROSSO DO SUL}

Em 2009 foram fixadas as normas de oferta da educação profissional técnica de nível médio no Sistema Estadual, por meio da Deliberação CEE/MS n. 9.195, de 30 de novembro de 2009, cujo objetivo foi consolidar o Ensino Médio e Técnico no Estado. O Conselho Estadual de Educação considerou que "a educação profissional e tecnológica, [...] integra-se aos diferentes níveis e modalidades de educação e às dimensões do trabalho, da ciência e da tecnologia". Sendo assim, postulou que esta abrange os seguintes cursos e programas: 
a) de Formação inicial e continuada ou qualificação profissional: constituída "pelos cursos e programas de formação incluindo capacitação, aperfeiçoamento e atualização, podendo [...] ser desenvolvida no ambiente de trabalho, independente de escolaridade, e não estão sujeitos à autorização prévia do órgão competente do Sistema Estadual de Ensino" (CEE/MS n. 9.195/2009, Art. 1ㅇ);

b) Educação profissional técnica de nível Médio: "destinada a proporcionar habilitação profissional a estudantes egressos do ensino fundamental e a estudantes matriculados ou egressos do ensino médio, e será oferecida de acordo com o disposto nesta Deliberação" (CEE/ MS n. 9.195/2009, Art. 1ㅇ);

c) Educação profissional tecnológica de graduação e pós-graduação: "correspondente a cursos de educação superior na área tecnológica destinados a egressos do ensino médio ou de graduação, respectivamente, e regular-se-ão pela legislação e normas pertinentes" (CEE/MS n. 9.195/2009, Art. 1우).

A deliberação CEE/MS n. 9.195/2009, que "fixa normas para a oferta da educação profissional técnica de nível médio no Sistema Estadual de Ensino de Mato Grosso do Sul e dá outras providências", apresenta essa modalidade educacional de ensino "oferecida somente a quem já tenha concluído o ensino fundamental, sendo o curso planejado de modo a assegurar ao aluno a habilitação profissional técnica de nível médio na mesma instituição de ensino, efetuando-

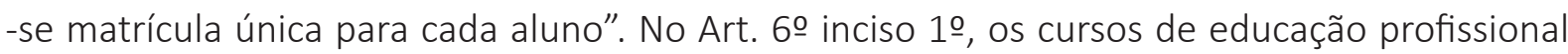
técnica de nível médio, ofertados de forma integrada ao ensino médio, devem ser estruturados em consonância com o previsto no inciso I do art. 24 da Lei n. 9.394/96, que exige uma carga horária mínima anual de "oitocentas horas, distribuídas por um mínimo de duzentos dias de efetivo trabalho escolar, excluído o tempo reservado aos exames finais, quando houver" (BRASIL, 1996, inciso I, art. 24).

Referente à carga horária sobre a educação profissional, no Estado de Mato Grosso do Sul a Deliberação CEE/MS n. 9.195/2009, Art. 60 estabelece que esta deve ser de, no mínimo, "3.000 horas para as habilitações profissionais que exigem o mínimo de 800 horas; [...] 3.100 horas para aquelas que exigem o mínimo de 1.000 horas; [e de] 3.200 horas para aquelas que exigem o mínimo de 1.200 horas"

$O$ referido documento restringe essa oferta de ensino somente às instituições que compõem o Sistema de Ensino Estadual de Mato Grosso do Sul Art. 3ํ, inciso 3, isto é, não possibilita que o aluno seja transferido para outro curso técnico, após ter iniciado um determinado currículo. Tal limitação se impõe em virtude das especificidades técnicas que cada programa requer para a formação dos alunos. Quanto ao Diploma expedido pelo referido curso, este tem validade, segundo o art. 39 "tanto para fins de habilitação profissional quanto para fins de certificação do ensino médio, possibilitando a continuidade de estudos na educação superior". A Deliberação, ainda prevê que a oferta do Ensino Técnico Integrado ao Ensino Médio na modalidade de Educação para Jovens e Adultos, contudo com carga horária distintas dos Cursos destinados àqueles que terminaram o Ensino Fundamental. Para a modalidade de Jovens e Adultos, a referida Deliberação estabeleceu o mínimo de "1.200 horas destinadas à educação geral, acrescida da carga horária mínima estabelecida para a habilitação profissional técnica de nível médio, de acordo com o Catálogo Nacional de Cursos Técnicos" Art. 6§2‥ No Art. 74, os Cursos Técnicos integrados ao Ensino Médio são regidos pelo referido documento e por normas específicas. 
Em síntese, podemos dizer que o Estado de Mato Grosso do Sul, além de seguir suas próprias diretrizes, colocou em prática as determinações do Ministério da Educação, no que diz respeito à implantação dos Cursos Técnicos em Geral e, de modo particular, dos Cursos Técnicos Integrados ao Ensino Médio. De acordo com Carmo (2012; 2010), a criação dos Cursos destinados ao Ensino Profissionalizante (Cursos Técnicos como tal, e o Curso Técnico integrado ao Ensino Médio), foi fruto da crescente industrialização, da criação do Sistema FIEMS e do apoio do governo Estadual em parceria com o Governo Federal.

Tabela 1 - Legislações

\begin{tabular}{|c|c|c|c|}
\hline ANO & ORIGEM & ID & DESCRIÇÃO E FINALIDADE \\
\hline 1977 & MS & Lei Complementar n.31 & $\begin{array}{l}\text { Cria o Estado de Mato Grosso do Sul, e dá outras } \\
\text { providências. }\end{array}$ \\
\hline 1989 & MS & Constituição do MS & Constituição do MS. \\
\hline 1984 & MS & Lei n. 440 & $\begin{array}{l}\text { Cria o Conselho de Desenvolvimento Industrial do Es- } \\
\text { tado de Mato Grosso do Sul e concede os incentivos } \\
\text { que menciona }\end{array}$ \\
\hline 1979 & MS & Resolução n. 323.051 & Cria da FIEMS \\
\hline 1996 & $\mathrm{BR}$ & Lei n. 9.394 & $\begin{array}{l}\text { Estabelece as diretrizes e bases da educação nacional. } \\
\text { Brasília }\end{array}$ \\
\hline 1980 & SED/MS & Resolução n. 016 & $\begin{array}{l}\text { Reconhece as habilitações em Técnico em Eletrotéc- } \\
\text { nica e Técnico em Enfermagem. }\end{array}$ \\
\hline 2001 & CEE & Deliberação CEE/MS n. 6.321 & $\begin{array}{l}\text { Fixa normas para a Educação Profissional de nível } \\
\text { técnico para o Sistema Estadual de Ensino de MS e dá } \\
\text { outras providências }\end{array}$ \\
\hline 2003 & CEE & Deliberação CEE/MS n. 7.014 & $\begin{array}{l}\text { Dispões obre a inclusão do } § 3 \text { o no Art. 5o e a su- } \\
\text { pressão do } \S 4 \text { o do Art. } 1 \text { 6, da Deliberação CEE/MS } \\
\text { no } 6321 \text {, de } 17 \text { de agosto de } 2001 \text {. }\end{array}$ \\
\hline 2004 & $\mathrm{BR}$ & Decreto 5.154 & $\begin{array}{l}\text { Regulamenta o } § 20 \text { do art. } 36 \text { e os arts. } 39 \text { a } 41 \text { da Lei } \\
\text { n. } 9.394 \text {, de } 20 \text { de dezembro de } 1996 \text {, que estabelece } \\
\text { as diretrizes e bases da educação nacional, e dá out- } \\
\text { ras providências }\end{array}$ \\
\hline 2005 & CEE & Deliberação CEE/MS n. 7.860 & $\begin{array}{l}\text { Dispõe sobre o Estágio Supervisionado, no Sistema } \\
\text { Estadual de Ensino de Mato Grosso do Sul e dá outras } \\
\text { providências }\end{array}$ \\
\hline 2008 & CEE & Deliberação CEE/MS n. 8.830 & $\begin{array}{l}\text { Dispõe sobre a implantação do Catálogo Nacional de } \\
\text { Cursos Técnicos de Nível Médio (CNCT) no Sistema } \\
\text { Estadual de Ensino de Mato Grosso do Sul. }\end{array}$ \\
\hline 2009 & CEE & Deliberação CEE/MS n. 9.195 & $\begin{array}{l}\text { Fixa normas para a oferta da educação profissional } \\
\text { técnica de nível médio no Sistema Estadual de Ensino } \\
\text { de Mato Grosso do Sul e dá outras providências. }\end{array}$ \\
\hline
\end{tabular}

Fonte: Elaboração própria.

\section{CONSIDERAÇÕES FINAIS}

O objetivo do estudo foi identificar as ações do Estado do MS e da FIEMS sobre as políticas de educação profissional e técnica por meio de alguns documentos. Essa preocupação ocorre na esfera das novas formas de organização da produção capitalista.

Em um primeiro momento, na tentativa de situar a criação da Federação das Indústrias em Mato Grosso do Sul, verificou-se a constituição do novo empresariado nas décadas de 1980 e 1990 e quais foram as suas reivindicações no contexto das transformações econômicas e políticas. Nesse período, foi possível identificar mudanças significativas no empresariado quanto aos seus 
interesses, na diversificação da estrutura empresarial e sua expansão, por meio de organizações corporativas oficiais e por associações independentes. Essa expansão centra-se, dentre outras coisas, no questionamento da atuação das entidades tradicionais que representam os interesses da classe empresarial, pelo esforço de superar a visão particularista, setorial e de curto prazo, típica dos padrões convencionais de comportamento do empresariado.

Foi, ainda, identificado que tais mudanças ocorridas na estrutura empresarial estão inerentemente atreladas com o Estado e que não há dúvidas de que o processo de mudança atualmente em curso na economia e do setor privado, em parte, é resultado da própria ação empresarial suas associações e dirigentes, como também é decorrência de amplas e completas alianças de forças (externas e internas) que vão criando as condições para alterar as funções do Estado quanto às políticas públicas.

No segundo momento, verificou-se a criação da Federação das Indústrias em Mato Grosso do Sul. Essa ocorrência se deu com o surgimento do Estado de MS, junto com o seu desenvolvimento econômico, por meio de programas que possibilitaram incentivos fiscais e econômicos, acentuando o processo de industrialização no setor secundário. Identificou, ainda, que, com a criação do Estado, houve por parte dos empresários da FIEMS a cobrança para incentivos à indústria sendo correspondida, vindo a consolidar o processo de industrialização no Estado. Essa consolidação acompanhou investimentos na qualificação profissional, preocupação da FIEMS que esteve centrada na formação profissional. Isso foi possível perceber por meio da identificação dos projetos, dos investimentos e os seus beneficiários.

Em um quarto momento, procurou-se identificar a educação profissional e ensino técnico profissional no estado do Mato Grosso do Sul quanto aos seus aspectos legais. Verificou-se que a finalidade do Estado foi reconhecer, por meio, das legislações novas habilitações de cursos Técnicos em várias áreas, compreendidos no contexto de crescimento econômico do Estado. Este, por sua vez, assegurava o direito de os alunos realizarem o Estágio Supervisionado em entidades subvencionadas pelo Estado, que assegurava à criança, ao adolescente e ao jovem o direito a Profissionalização.

Quanto a políticas voltadas para o campo, o Estado tinha o dever de implantar e manter núcleos de profissionalização específica destinados ao homem do campo, levando em conta as peculiaridades locais, visando desenvolver e consolidar a diversificação e a especialização regionais. Essas ocorrências seguiram todo o processo de implementação de políticas econômicas, no contexto de transformações no setor produtivo e do trabalho.

Por fim, verificou-se que o Ensino Técnico integrado ao Ensino Médio no Estado de Mato Grosso do Sul foi fixado em 2009 pelo Estado, com vistas a consolidar esse nível e modalidade educacional. O Estado, por meio do seu Conselho de Educação, considerou a educação profissional e tecnológica parte integrante dos diferentes níveis e modalidades de educação, e as dimensões do trabalho, da ciência e da tecnologia atreladas a esse nível e modalidade educacional, dessa forma, acompanham o Decreto 5.154/2004.

\section{REFERÊNCIA}

ABREU, Silvana de. Planejamento governamental: a SUDECO no espaço mato-grossense. 2001. $328 f$. Tese (Doutorado em Geografia) - Faculdade de Filosofia, Letras e Ciências Humanas da Universidade de São Paulo, São Paulo, 2001. Disponível em: <http://www.teses.usp.br/teses/disponiveis/8/8136/tde28022002-232232/pt-br.php>. Acesso em: 15 maio 2016. 
BIANCHI, Alvaro. O ministério dos industriais: a Federação das Indústrias do Estado de São Paulo na crise das décadas de 1980 e 1990. Campinas, SP: Editora da UNICAMP, 2010. 10 sem. 2004.

Estado e empresários na América Latina (1980-2000). Antropolítica, Niterói, RJ, n. 16, p. 101-22,

BRASIL. Resolução CNE/CEB n. 1, de 3 de fevereiro de 2005. Atualiza as Diretrizes Curriculares Nacionais definidas pelo Conselho Nacional de Educação para o Ensino Médio e para a Educação Profissional Técnica de nível médio às disposições do Decreto no 5.154/2004. Disponível em: <http://portal.mec.gov.br/cne/ arquivos/pdf/rceb001_05.pdf>.

. Decreto n. 5.154, de 23 de julho de 2004. Regulamenta o $\S 20$ do art. 36 e os arts. 39 a 41 da Lei n. 9.394, de 20 de dezembro de 1996, que estabelece as diretrizes e bases da educação nacional, e dá outras providências. Disponível em: <http://www.planalto.gov.br/ccivil_03/_ato2004-2006/2004/ decreto/d5154.htm>.

. Lei n. 9.394, de 20 de dezembro, 1996. Estabelece as Diretrizes e Bases da Educação Nacional. Brasília, 1996. Disponível em: <http://www2.camara.gov.br/legin/fed/lei/1996/lei-9394-20- dezembro1996-362578-norma-pl.html>. Acesso em: 15 ago. 2016.

Resolução n. 323.051/79, de 21 de novembro, 1979. Cria a FIEMS. Disponível em: <https://www. jusbrasil.com.br/diarios/3396870/pg-4-secao-2-diario-oficial-da-uniao-dou-de-21-11-1979?ref=next_ button>. Acesso em: 26 jan. 2016.

. Lei Complementar n. 31, de 11 de outubro, de 1977. Cria o Estado de Mato Grosso do Sul, e dá outras providências. Disponível em: <http://www.planalto.gov.br/ccivil_03/leis/lcp/lcp31.htm>. Acesso em 15 out. 2016.

. Ministério do Interior. Superintendência do Desenvolvimento da Região Centro-Oeste-SUDECO. II Plano Nacional de Desenvolvimento; programa de ação do governo para a Região Centro-Oeste - 1975 - 1979. Brasília, 1975.

. Ministério do Interior. Superintendência do Desenvolvimento da Região Centro-Oeste-SUDECO. Plano de desenvolvimento econômico-social do Centro-Oeste - PLADESCO. Brasília: SUDECO, 1973.

. I Plano Nacional de Desenvolvimento (PND) - 1972/74. Brasília: IBGE, 1971.

CARMO, Jefferson Carriello do. Ações do governo do Estado de Mato Grosso do Sul para o crescimento industrial, no segundo setor, e a educação profissional. In: KASSAR, Mônica de Carvalho Magalhães; SILVA, Fabiany de Cássia Tavares (Org.). Educação e pesquisa no Centro-Oeste: políticas públicas e desafios na formação humana. Campo Grande, MS: Ed. UFMS, 2012.

. Política de educação e desenvolvimento industrial na gênese da constituição do Estado do Mato Grosso do Sul e do município de Campo Grande (1970- 1980). In: JORNADA DO HISTEDBR, 10., História da educação: intelectuais, memória e política. Anais... Vitória da Conquista, BA: UESB, 2011. 1 CD-Rom.

Formas de produção e trabalho e as políticas públicas de educação profissional integrada ao ensino médio no Estado de Mato Grosso do Sul. Projeto de Pesquisa apresentado ao Processo de Seleção de Projetos para o Edital MCT/CNPq n. 014/2010 - Universal. Campo Grande, MS, 2010.

CONSELHO DE DESENVOLVIMENTO E INTEGRAÇÃO SUL (CODESUL). História. Campo Grande; Curitiba; Florianópolis, Porto Alegre. Disponível em: $<$ http://www.codesul.com.br/conteudos.php?p=4>. Acesso em: 25 fev. 2017.

CRUZ, Sebastião Carlos Velasco. Empresariado e Estado na transição brasileira: um estudo sobre a economia política do autoritarismo (1974-1977). Campinas, SP: Editora da UNICAMP; São Paulo: FAPESP, 1995.

DINIZ, Eli; BOSCHI, Renato. Globalização, herança corporativa e a representação dos interesses empresariais: novas configurações no cenário pós-reformas. In: DINIZ, Eli; BOSCHI, Renato; SANTOS, Fabiano. Elites políticas e econômicas no Brasil contemporâneo: a desconstrução da ordem corporativa e o papel do legislativo no cenário pós-reforma. São Paulo: Fundação Konrad Adenauer, 2000. 
Brasil: um novo empresariado? Balanço de tendências recentes. In: DINIZ, Eli (Org.). Empresário e modernização econômica: Brasil anos 90. Florianópolis: Editora UFSC/IDACON, 1993.

DINIZ, Eli; BOSCHI, Renato; SANTOS, Fabiano. Elites políticas e econômicas no Brasil contemporâneo: a desconstrução da ordem corporativa e o papel do legislativo no cenário pós-reforma. São Paulo: Fundação Konrad Adenauer, 2000.

DURAND, Francisco. Os novos empresários (e alguns problemas de idade). Nueva Sociedad, n. 151, p. 73-87, set./out. 1997.

FEDERAÇÃO DAS INDÚSTRIAS DE MATO GROSSO DO SUL (FIEMS). Ação FIEMS: ano de comemoração é também marco de investimento para ampliar atendimento. Revista da Federação das Indústrias de Mato Grosso do Sul, ano 02, n. 12, 2009a.

Ação Sesi: Ensino para jovens e adultos garante novas oportunidades para trabalhadores. Revista da Federação das Indústrias de Mato Grosso do Sul, ano 02, n. 12, 2009b.

. FIEMSinova: gestão integrada envolve diretores em 12 projetos estratégicos e produtivos. Revista da Federação das Indústrias de Mato Grosso do Sul, ano 02, n. 12, 2009c.

FEDERAÇÃO DAS INDÚSTRIAS DE MATO GROSSO DO SUL (FIEMS); SERVIÇO NACIONAL DE APRENDIZAGEM INDUSTRIAL (SENAI). Economia industrial de Mato Grosso do Sul: relatório técnico SENAI, SEBRAE. Campo Grande: FIEMS, SENAI, 2008.

FERNANDES, Alfredo. FIEMS - 30 anos: história e antecedentes. Revista da Federação das Indústrias de Mato Grosso do Sul, ano 02, n. 12, p. 9, 2009.

FLEURY, Afonso Carlos Corrêa. Rotinização do trabalho: o caso das indústrias mecânicas. In: FLEURY, Afonso Carlos Corrêa; VARGAS Nilton. Organização do trabalho. São Paulo: Atlas, 1994.

Organização do trabalho na indústria: recolocando a questão nos anos 80. In: FLEURY, Maria Tereza Leme; FISCHER, Rosa Maria (Coord.). Processo e relações do trabalho no Brasil. 2. ed. São Paulo: Atlas, 1992.

GIACALONE, Rita. Asociaciones empresariales integración y Estado Colombia y Venezuela. Nueva Sociedad, n. 151, p. 155-67, set./out. 1997.

LAMOSO, Lisandra Pereira. Dinâmicas produtivas da economia de exploração no Mato Grosso do Sul Brasil. Mercator, Fortaleza, v. 10, n. 21, p. 33-47, jan./abr. 2011.

LEITE, Marcia de Paula. Trabalho e sociedade em transformação: mudanças produtivas e atores sociais. São Paulo: Fundação Perseu Abramo, 2003.

Inovação tecnológica e relações de trabalho: a experiência brasileira à luz do quadro internacional. In: CASTRO, Nadya Araújo de (Org.). A máquina e o equilibrista: inovações na indústria brasileira. São Paulo: Paz e Terra, 1995.

Reestruturação produtiva, novas tecnologias e novas formas de gestão de mão-de-obra. In: OLIVEIRA, Carlos Alonso Barbosa de et al. O mundo do trabalho: crise e mudança no final do século. São Paulo: Scritta, 1994.

LONGEN, Sérgio Marcolino. Nosso tempo é agora. Revista da Federação das Indústrias de Mato Grosso do Sul, ano 02, n. 12, p. 3, 2009.

MATO GROSSO DO SUL. Deliberação CEE/MS n. 9.195, de 30 de novembro de 2009. Fixa normas para a oferta da educação profissional técnica de nível médio no Sistema Estadual de Ensino de Mato Grosso do Sul e dá outras providências. Disponível em: <http://www.cee.ms.gov.br/wp-content/uploads/ sites/84/2015/08/del-9195.pdf>. Acesso em: 4 abr. 2014.

Deliberação CEE/MS n. 8.830, de 10 de agosto de 2008. Dispõe sobre a implantação do Catálogo Nacional de Cursos Técnicos de Nível Médio - CNCT no Sistema Estadual de Ensino de Mato Grosso do Sul. Disponível em: <http://www.cee.ms.gov.br/wp-content/uploads/sites/84/2015/08/del-8830.pdf>. Acesso em: 22 abr. 2017. 
Deliberação CEE/MS n. 7.860, de 16 de setembro de 2005. Dispõe sobre o Estágio Supervisionado, no Sistema Estadual de Ensino de Mato Grosso do Sul e dá outras providências. Disponível em: <http:// www.cee.ms.gov.br/wp-content/uploads/sites/84/2015/08/del-7860.pdf>. Acesso em: 8 mar. 2017.

. Deliberação CEE/MS n. 7.014, de 16 de maio de 2003. Dispõe s obre a inclusão do § 3 no Art . 5o e a supressão do § 4ㅇ d o Art. 16, da Deliberação CEE/MS n. 6321, de 17 de agosto de 2001. Disponível em: <http://www.cee.ms.gov.br/wp-content/uploads/sites/84/2015/08/del-7014.pdf>. Acesso em: 15 mar. 2017.

. Deliberação CEE/MS n. 6.321, de 17 de agosto de 2001. Fixa normas para a Educação Profissional de nível técnico para o Sistema Estadual de Ensino de MS e dá outras providências. Disponível e: $<$ http:// www.cee.ms.gov.br/wp-content/uploads/sites/84/2015/08/del-6321.pdf>. Acesso em: 14 nov. 2016.

. Constituição do Estado de Mato Grosso do Sul. 1989. Disponível em: <https://www.tjms.jus.br/ webfiles/producao/SPGE/revista/20180111172735.pdf>. Acesso em: 7 jan. 2016.

. Lei n. 440, de 21 de março de 1984. Cria o Conselho de Desenvolvimento Industrial do Estado de Mato Grosso do Sul e concede os incentivos que menciona. Disponível em: <http://www.normasbrasil. com.br/norma/lei-440-1984-ms_134341.html>.

Resolução n. 016, de 20 de março de 1980. Reconhece as habilitações em Técnico em Eletrotécnica e Técnico em Enfermagem, da Escola Técnica "Marechal Rondon" com sede em Três Lagoas. Disponível em: <http://aacpdappls.net.ms.gov.br/appls/legislacao/sed/legased.nsf/e3258672435f390e042571340 05057a1/26d8c5f2bcbb91f104256f32004be3be?OpenDocument>.

NEVES, Lúcia Maria Wanderley (Org.). A nova pedagogia da hegemonia: estratégias do capital para educar o consenso. São Paulo: Xamã, 2005.

NEVES, Lúcia Maria Wanderley. Brasil ano 2000: uma nova divisão de trabalho na educação. São Paulo: Xamã, 2000.

. Educação e política no Brasil de hoje. São Paulo: Cortez, 1999.

OLIVEIRA, Ramon. Agências multilaterais e a educação profissional brasileira. Campinas, SP: Alínea, 2006.

. Empresariado industrial e a educação profissional brasileira. Educação e Pesquisa, São Paulo, v. 29, n. 2, p. 249-63, jul./dez. 2003.

RODRIGUES, José. O moderno príncipe industrial: o pensamento da Confederação Nacional da Indústria. Campinas, SP: Autores Associados, 1998.

SENNA, Ester (Org.). Política educacional de Mato Grosso do Sul na trajetória das políticas sociais. Campo Grande, MS: UFMS, 2000.

ZAHRAN, Jorge. Criação da FIEMS é fruto do sonho de industrialização do Estado. Revista da Federação das Indústrias de Mato Grosso do Sul, ano 02, n. 11, p. 8, 2009.

ZAMBERLAN, Carlos Otávio et al. Análise da industrialização sul-mato-grossense em face da industrialização brasileira. Revista Brasileira de Gestão e Desenvolvimento Regional, Taubaté, SP, v. 6. n. 3, p. 114-35, set./ dez. 2010.

\section{Sobre o autor:}

Jefferson Carriello do Carmo: Professor/Pesquisador do Programa de Pós-Graduação em Educação da Universidade de Sorocaba (UNISO). Mestre e Doutor em Educação Aplicada às Ciências Sociais (UNICAMP), Pós-Doutor em História Social do Trabalho - Departamento de História (UNICAMP). Coordenador do grupo de pesquisa Instituição Escolar: História, Trabalho e Políticas de Educação Profissional, CNPq. E-mail: jeffccprof@gmail.com; jefferson.carmo@prof.uniso.br 